\title{
SPATZ3 Intragastric Balloon: Efficacy, Fungal Contamination and Complications during the 12 Months of Use
}

\section{Bruno Queiroz Sander*, Oliveira ASB, Maiolini R, Pereira CRT, Sindorf ML, Ferreira CO, Silva MIF, Rosa ED, Barral MCM, Clasen SPAS, Freitas JBA, Benvenuti ECSC, Pessoa DF, Bonates HA, Scoralick MO, Ribeiro MMS, Matos CRQS, Carvalho CAM, Braga KM and Rosado JJS}

Bariatric Endoscopy Department, Sander Medical Center, Brazil

*Corresponding Author: Bruno Queiroz Sander, Bariatric Endoscopy Department, Sander Medical Center, Brazil.
Received: July 30, 2020

Published: August 08, 2020

(C) All rights are reserved by Bruno Queiroz Sander., et al.

\begin{abstract}
Introduction: The intragastric balloon is the medical treatment indicated for patients with overweight and obesity, it's safe and effective with great results all over the world. The presence of fungi on the external surface of the intragastric balloon has been the main cause of silicone fragility and perforation of the balloon, with the need for prosthesis replacement. One of the objectives of this study will be to evaluate the effectiveness of the use of oral anti fungal medication (Nystatin) to try to reduce the appearance of fungi on the surface of the balloon and, thus, try to also reduce the rate of leakage or rupture of the prosthesis, in addition, this study aims to evaluate the effectiveness of Spatz in weight loss, as well as the complications presented during the period of its use. We divided the 268 participants in this study into two distinct groups: In the first group, we mixed Nystatin with the usual balloon filling solution and in the second group, we used only the usual filling solution, without the use of anti fungal.

Results: In the group where anti-fungal was placed in the balloon filling solution, a little less than $10 \%$ of fungal patency was observed on the surface of the balloon, while in the other group, without the anti-fungal, this prevalence was close to $20 \%$, or that is, almost twice as much. We did not observe significant variations in fungal colonization in relation to the age or gender of the participants in this study. The appearance of ulcers, despite the considerable incidence, was not a problem and, in most cases, it was treated conservatively.

Conclusion: The use of anti fungal mixed with the usual filling solution of the balloon decreases the presence of fungi on its surface and, consequently, decreases the rate of perforation or early rupture of the prosthesis. Spatz proved to be a safe and very effective IGB as an auxiliary method for weight loss.
\end{abstract}

Keywords: SPATZ3; Intragastric Balloon; Fungal

\section{Introduction}

Since the year 2015, when it was approved by Anvisa in Brazil, the 12-month Spatz3 adjustable intragastric balloon has been used as an endoscopic method to assist in the weight loss process. In this time of use, some important aspects were observed in more than
2,500 procedures performed. One of these aspects is the presence of fungal colonization on the silicone surface, increasing the friability of the balloon and inducing rupture and deflation. In some cases, we also observed hyperinflation of gases inside the balloon, which may be related to the presence of these fungi. Thus, the ob- 
jective of this study was to evaluate whether the use of nystatin can be beneficial in reducing the incidence of fungal colonization on the external surface of the balloon and also to evaluate the effectiveness of Spatz3 in weight loss, as well as to analyze the complications presented during the period of its use.

\section{Methodology}

268 patients ( $81.9 \%$ women) who underwent the procedure to introduce the Spatz3 adjustable intragastric balloon over the years 2017 and 2018, participated in this study. Our focus was to evaluate the effectiveness of using an anti-fungal medication (nystatin), diluted with the usual intragastric balloon filling solution $10.9 \%$ saline $+4 \%$ methylene blue), to try to reduce the appearance of fungal plaques in the outer surface of the balloon. We divided patients into two distinct groups by randomized clinical trial: In 122 patients we used 50 milliliters of nystatin (100,000 IU/ML) mixed with the usual Spatz filling solution (Test Group). In the remaining 146 patients, we used only the usual solution (saline $0.9 \%+10 \mathrm{ml}$ of methylene blue 4\%) (control group). Only two nurses on the team, who took notes on the data, were aware of which participants received Nystatin in the balloon filling solution.

In all participants in this study, filling the Spatz3 with $700 \mathrm{ml}$ of solution was started. The minimum BMI of $27 \mathrm{~kg} / \mathrm{m}^{2}$ was stipulated to implant the balloon and the maximum period of use of the prosthesis was 12 months. Upon removal of the balloon, the endoscopist described the appearance of the silicone surface, reporting whether there were fungi. In cases where there was fungal colonization, we divided the description into four levels, depending on the surface area affected: less than 10\% (normal), between $10 \%$ and 25\% (discrete), between 20 and 50\% (moderate) and more $50 \%$ (intense).

In addition to these data, we also evaluated the efficacy in relation to weight loss and the complications observed during the period of use of the IGB.

All patients signed the Free and Informed Consent Form (ICF) to participate in the research and all ethical guidelines were followed.

\section{Results}

In the final analysis, 36 participants were excluded $(13.85 \%$ from the initial sample): $03(1.12 \%)$ for giving up treatment in the first 30 days of using the IGB, 19 (7.1\%) for having made ad- justments in the balloon volume over the 12 months of use, 07 $(2,61 \%)$ for removing the prosthesis before 09 months of use and $07(2.61 \%)$ for having leaked and needing to undergo prosthesis replacement. The average age of the participants was 32.12 years ( \pm 42.8 years) and the average weight loss over 12 months was $22.72 \mathrm{~kg}( \pm 21.9 \mathrm{~kg})$.

Among the 232 patients who were part of the final analysis, 109 had Nystatin mixed with the balloon filling solution and $123 \mathrm{had}$ only saline and methylene blue inside the balloon. In the test group (using antifungal), the total prevalence of colonization by fungi on the prosthesis surface was $9.17 \%(n=10)$. Of this total, $07(70 \%)$ demonstrated discrete colonization, 02 (20\%) moderate colonization and $01(10 \%)$ intense colonization. In the control group (without the use of anti-fungal) the total incidence of colonization by fungi was $19.51 \%(n=24)$ : 09 (37.5\%) with discrete colonization, $10(41.67 \%)$ moderate colonization and 05 (20.83\%) intense colonization. The results showed no significant difference by gender or age.

The mean Percent EWL was 69.61\% (12 months). Mean weight loss was $22.72 \mathrm{~kg}$ (12 months). Mean variation of BMI was $6.88 \mathrm{~kg} /$ $\mathrm{m}^{2}$ (12 months). Removal due to initial intolerance was only $1.12 \%$. Nonetheless, regarding intercurrences and complications, the 12 months balloon presented a considerable incidence of gastric perforation $(0,24 \%)$, bleeding due to Dieulafoy lesion $(0,2 \%)$, Spontaneous deflation $(2,61 \%)$, migration and passage in stool $(0,91 \%)$ and ulcers $(4,2 \%)$. The appearance of ulcers was higher from the sixth month of balloon usage $(61,1 \%)$ and the most used approach was changing the balloon or a dose increase of IBP $(89,7 \%)$. In only $10,3 \%$ of ulcer cases, the IGB removal was necessary.

\section{Discussion and Conclusion}

We do not yet know how fungal contamination occurs on the surface of the intragastric balloon. However, there are theories that this contamination happens from the moment of insertion of the device in the stomach or that it is favored by the lowering of the $\mathrm{pH}$ of the stomach by the use of PPI. What we can say is that as one of the mechanisms of action of the balloon is the delay in gastric emptying, the presence of the direct contact of the food ingested with the silicone surface for a prolonged time, facilitates the proliferation of fungi. We also know that fungi, like Candida albicans, form biofilms more easily in the balloon's silicone [1-12]. 
We observed that mixing Nystatin to the balloon filling solution reduced the incidence of fungi on the silicone surface by half. Thus, we can deduce that this practice has a positive effect on the prevention of fungus, with low cost and a significant difference. However, as we observed such a low deflation rate of Spatz3 in this total sample (2.61\%), it is questioned whether the use of anti-fungals would be necessary to prevent such a discrete problem, which occurs with such a low frequency and it does not bring any severe consequences to the patient. It is also important to note that the 34 patients who had fungi on the surface of the balloon $14.66 \%$ of the final sample) did not present any type of clinical symptom related to the fungus. The appearance of ulcers, despite the considerable incidence $(4,2 \%)$, was not a problem since only $10,3 \%$ of patients with this alteration had to remove the IGB.

Thus, Spatz3 proved to be a safe and very effective IGB as an auxiliary method for weight loss.

\section{Bibliography}

1. Sander BQ., et al. "Intragastric Balloon: A Large Brazilian Multicentric Study Over 10,000 Cases and 20 Years of Experience". Advanced Research in Gastroenterology and Hepatology (ARGH) 12.3(2019):4.

2. Ashrafian H., et al. "Intragastric balloon outcomes in super-obesity: a 16-year city center hospital series". Surgery for obesity and related diseases: official journal of the American Society for Bariatric Surgery 14.11(2018): 1691-1699.

3. Coskun H and Bozkurt S. "A case of asymptomatic fungal and bacterial colonization of an intragastric balloon". World Journal of Gastroenterology 15.45(2009):5751-5753.

4. Ribeiro da Silva J., et al. "Intragastric Balloon for Obesity Treatment: Safety, Tolerance, and Efficacy". GE Portuguese Journal of Gastroenterology 25.5(2018): 236-242.

5. Kotzampassi K., et al. "Candida albicans colonization on an intragastric balloon". Asian Journal of Endoscopic Surgery 6.3(2013):214-216.

6. Tate CM and Geliebter A. "Intragastric Balloon Treatment for Obesity: FDA Safety Updates". Advances in therapy 35.1(2018): $1-4$.

7. Neto MG., et al. "Brazilian Intragastric Balloon Consensus Statement (BIBC): practical guidelines based on experience of over 40,000 cases". Surgery for Obesity and Related Diseases 14.2(2018):151-159.
8. Abu Dayyeh BK. "Intragastric Balloons for Obesity Management". Gastroenterology and Hepatology 13.12(2017): 737739.

9. Nguyen V., et al. "Outcomes following Serial Intragastric Balloon Therapy for Obesity and Nonalcoholic Fatty Liver Disease in a Single Centre". Canadian Journal of Gastroenterology and Hepatology (2017): 4697194.

10. Rajablou M., et al. "Candida infection presenting as multiple ulcerated masses". Gastrointestinal Endoscopy 65.1(2007):164166.

11. Konnopka A., et al. "The Costs of Overweight and Obesity: a Systematic Review”. Gesundheitswesen 80.5(2018): 471-481.

12. da Silveira LC., et al. "Biofilm formation by Candida species on silicone surfaces and latex pacifier nipples: an in vitro study". Journal of Clinical Pediatric Dentistry 33.3(2009):235-240.

\section{Assets from publication with us}

- Prompt Acknowledgement after receiving the article

- Thorough Double blinded peer review

- Rapid Publication

- Issue of Publication Certificate

- High visibility of your Published work

Website: www.actascientific.com/

Submit Article: www.actascientific.com/submission.php

Email us: editor@actascientific.com

Contact us: +919182824667 